the chapters being arranged alphabetically. Thus 'Technique of examination' is sandwiched between 'Right lower quandrant disease' and 'Trauma to the colon and rectum'. This is not so confusing as it sounds, because this is not a book to be read through from cover to cover. It is one to dip into when seeking information. In spite of its title it cannot be regarded as an introductory text. It will, however, be a very welcome addition to the library in departments of gastroenterology and radiology.

KELSEY FRY

\begin{abstract}
Notebook of Medical Physiology: Gastrointestinal with Aspects of Total Parenteral Nutrition By Ross W Hawker. (Pp. 246. Illustrated. $£ 4 \cdot 95$.) Churchill Livingstone: Edinburgh, London, Melbourne, and New York. 1981.
\end{abstract}

This book is a 'revision text for ... postgraduates' and the author admits that its 'unique' style, deliberately cryptic, will not please everyone. It covers the normal physiological mechanisms involved in secretion, absorption, digestion and motility of the tract and in gastrointestinal liver function. It starts with a short factual account of gut hormones, which is followed by the excellent physiology sections. The final chapters on the assessment of gastrointestinal function are superficial. The chapters are written in the form of notes which are occasionally difficult to understand. Each chapter is followed by a series of multiple-choice questions and answers.

The physiology chapters, very detailed and extensive, are made up of notes, tables, and flow diagrams. Sometimes these diagrams are too complicated and need some explanation. The principles of carbohydrate metabolism, for example, are summarised in a small illustration with 17 abbreviations (some explained) and one has to strain to read the small print and follow the arrows. Physiological principles are presented well but there is no space in a 'notebook' to discuss any controversial points. Histamine's role as final mediator of gastric acid secretion is accepted without much discussion and mention is not made of $\mathrm{K}^{+}$ATPase. Gastric mucus is dismissed in seven lines and the newish concept of cytoprotection has been omitted. However, the book is only supposed to be a notebook and a list of useful review and original papers follows each section. The final chapter is a practical guide on how to set up and manage total parenteral nutrition and, as such, is quite out of place in a physiology book. A description of the physiological principles governing both enteral and parenteral nutrition would have been more appropriate.

This book is a successful attempt to summarise gastrointestinal physiology and one becomes used to the initially unnerving style. An enormous amount of information is packed into the physiology sections, which are a welcome addition to a personal library. Few postgraduates would tolerate the style for revision. Although cheap, the book is nicely presented and will be a useful rapid reference book.

R P WALT

Nutrition and its Disorders 3rd edition. By D S McLaren. (Pp. 277. Illustrated. £5.95.) Churchill Livingstone: Edinburgh and London. 1981.

To compress the whole enormous field of nutrition-normal, abnormal, and therapeutic-into a 270 page volume is an extraordinary achievement, especially when the result is lucid, readable, and, mostly, up to date. The book is laid out in six sections, on food and the physiology of nutrition, on nutritional diseases, on the role of diet and nutrition in other diseases, on nutritional disorders at different ages, on nutritional 'interrelationships' (topics such as immunity and drugs), and on community aspects.

As a short overview of the subject, this book has no serious rival but for the serious enquirer it is strictly a starting point. Gastroenterologists will be disappointed by the section on the gastrointestinal system, which, surprisingly, is said to have 'resisted investigation and understanding more than most systems'. Perhaps the author has lacked time and opportunity to study gastroenterology, but there are many inaccuracies. Two areas of intense interest-enteral nutrition and dietary fibre-receive scanty treatment. In fact, the whole sweep of the fibre story is dismissed in half a page. The sections on alcohol and cancer are also too short considering their importance to society.

The worlds of nutrition and medicine have become seriously separated from each other in recent years. It is the gut which bridges the gap between food and the body and gastroenterologists are the most appropriate people to repair the links between nutrition and medicine. It would help if they and their students browsed through this book.

K W HEATON

\section{Delay in publication}

We much regret the delay in the appearance of Gut because of printing difficulties. 